\title{
Consolidated and Labile Odor Memory Are Separately Encoded within the Drosophila Brain
}

\author{
Lisa Scheunemann, ${ }^{1}$ Eva Jost, ${ }^{2}$ Antje Richlitzki, ${ }^{1}$ Jonathan P. Day, ${ }^{3}$ Sujith Sebastian, ${ }^{3}$ Andreas S. Thum, ${ }^{4,5}$ \\ Marina Efetova, ${ }^{1}$ Shireen-A. Davies, ${ }^{3}$ and Martin Schwärzel ${ }^{1}$ \\ ${ }^{1}$ Biology-Genetics, Free University Berlin, D-14195 Berlin, Germany, ${ }^{2}$ Veterinary Medicine, Ludwig-Maximilians University Munich, D-80539 Munich, \\ Germany, ${ }^{3}$ Institute of Molecular, Cell and Systems Biology, College of Medical, Veterinary and Life Sciences, University of Glasgow, Glasgow G12 8QQ, \\ United Kingdom, ${ }^{4}$ Department of Biology, University of Fribourg, CH-1700 Fribourg, Switzerland, and ${ }^{5}$ Department of Biology, University of Konstanz, \\ D-78464 Konstanz, Germany
}

Memories are classified as consolidated (stable) or labile according to whether they withstand amnestic treatment, or not. In contrast to the general prevalence of this classification, its neuronal and molecular basis is poorly understood. Here, we focused on consolidated and labile memories induced after a single cycle training in the Drosophila aversive olfactory conditioning paradigm and we used mutants to define the impact of cAMP signals. At the biochemical level we report that cAMP signals misrelated in either rutabaga (rut) or dunce (dnc) mutants separate between consolidated anesthesia-resistant memory (ARM) and labile anesthesia-sensitive memory (ASM). Those functionally distinct cAMP signals act within different neuronal populations: while rut-dependent cAMP signals act within Kenyon cells (KCs) of the mushroom bodies to support ASM, dnc-sensitive cAMP signals support ARM within antennal lobe local neurons (LNs) and KCs. Collectively, different key positions along the olfactory circuitry seem to get modified during storage of ARM or ASM independently. A precise separation between those functionally distinct cAMP signals seems mandatory to allocate how they support appropriate memories.

\section{Introduction}

The memory consolidation theory sorts memory according to whether it withstands an amnestic treatment, or not (Lechner et al., 1999). In Drosophila aversive olfactory learning, two different types of consolidated (stable) memories have been characterized: long-term memory (LTM), which relies on de novo protein synthesis, and anesthesia-resistant memory (ARM), which does not (Tully et al., 1994; Yin et al., 1994). In contrast to LTM, ARM is induced by a single cycle training and is an integral component of mid-term memory (MTM) typically quantified at $3 \mathrm{~h}$ after conditioning (Tully et al., 2003). Another memory phase reliably induced by single cycle training and adhered within MTM is anesthesia-sensitive memory (ASM), which is sensitive to retrograde amnesia and erased by experimental cooling (Tempel et al., 1983). Based on the finding that ASM, but not ARM, is affected in rutabaga (rut) mutants, Isabel et al. (2004) suggested that these memories are independently acquired.

Recent advancements have transformed Drosophila from a model to define the genetic basis of those memories into a model to

\footnotetext{
Received July 10, 2012; revised 0ct. 1, 2012; accepted 0ct. 3, 2012.

Author contributions: M.E. and M.S. designed research; L.S., E.J., A.R., S.S., and A.S.T. performed research; J.P.D. and S.-A.D. contributed unpublished reagents/analytic tools; L.S., E.J., A.R., A.S.T., and M.E. analyzed data; S.-A.D. and M.S. wrote the paper.

This work was supported by Deutsche Forschungsgemeinschaft (DFG) Grant SCHW1410/1-1 to M.S. and DFG Grant TH1584/1-1, Schweizer Nationalfonds Grant 31003A_132812/1 and the Zukunftskolleg of the University Konstanz to A.S.T., and Biotechnology and Biological Sciences Research Council (UK) Grant BB/C000633/1 to S.D.. Essential fly stocks were obtained from the Bloomington Stock Center (Indiana).

Correspondence should be addressed to Martin Schwärzel, Free University Berlin, Biology-Genetics, Takustrasse 6, D-14195 Berlin, Germany. E-mail: martin.schwaerzel@fu-berlin.de.

DOI:10.1523/JNEUROSCI.3286-12.2012

Copyright $\odot 2012$ the authors $\quad 0270-6474 / 12 / 3217163-09 \$ 15.00 / 0$
}

understand the neuronal circuitry function supporting them. Kenyon cells (KCs) of the mushroom bodies (MBs) have received considerable attention, as they form one critical neuron population of a larger circuit engaged for support of odor memories. MBs represent an anatomical convergence point for conditioned stimulus (CS) and unconditioned stimulus (US)-related impulses, i.e., neuronal representations of the olfactory cue - the CS - and electric shock reinforcement - the US. Synaptic plasticity within MB intrinsic neurons is regulated by the $\mathrm{CAMP} / \mathrm{PKA}$ (protein kinase A) pathway and represents a critical molecular signal for support of either ARM or ASM (Schwaerzel et al., 2007; Horiuchi et al., 2008; Knapek et al., 2011). $\mathrm{Ca}^{2+}$-sensitive type 1 adenylyl cyclase (AC1) and cAMPspecific type 4 phosphodiesterase (PDE4) affected in Drosophila learning mutants rutabaga (rut-AC1) and dunce (dnc-PDE4) affect very different aspects of cAMP signaling: while AC1 is proposed to act as contiguity detector for $\mathrm{Ca}^{2+} /$ calmodulin and G-protein signals (Abrams and Kandel, 1988), PDE4 is involved in restricting cAMP signals to particular subcellular locations (Houslay, 2010). Intriguingly, recent imaging studies showed that both aspects of cAMP signaling, e.g., rut-dependent detection of CS/US contingency and dnc-dependent compartmentalization of cAMP signals, were engaged in KCs under experimental conditions that resembled olfactory conditioning (Tomchik and Davis, 2009; Gervasi et al., 2010).

Here, we performed genetic rescue of $r u t^{1}$ and $d n c^{1}$ mutants within a side-by-side comparison and report that labile ASM and consolidated ARM are doubly dissociated on biochemical and neuronal levels. We show that ASM requires rut-AC1 within KCs, while consolidated ARM required dnc-PDE4 within KCs and local neurons of antennal lobes (ALs). Our 

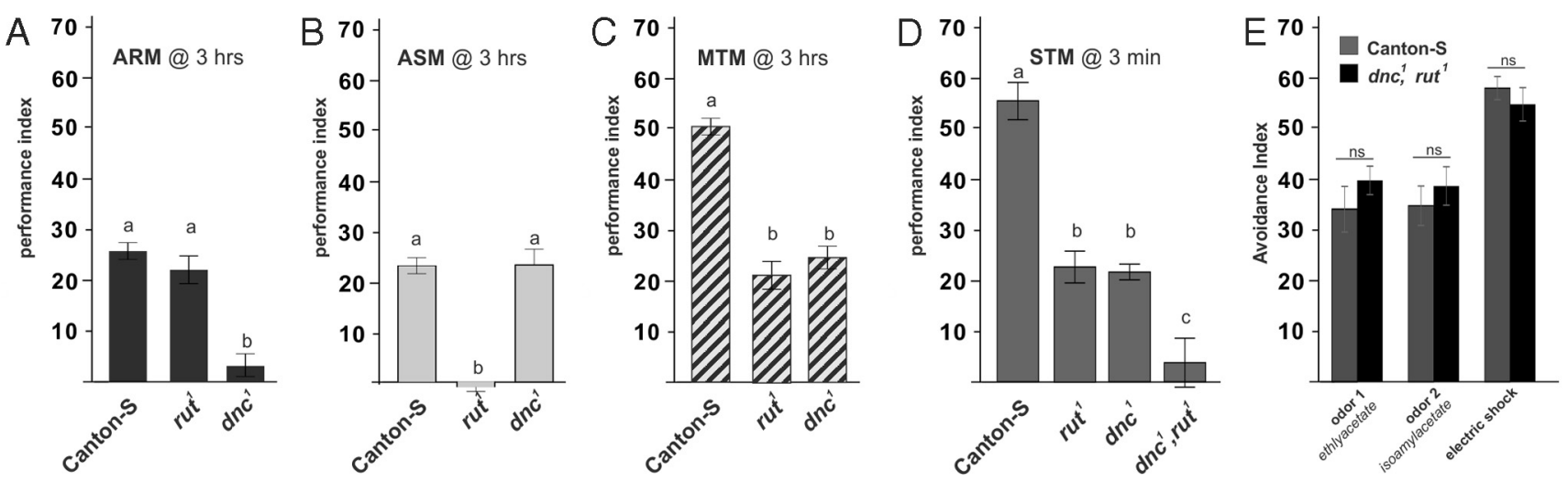

Figure 1. The cAMP signaling mutants $d n c^{7}$ and rut ${ }^{7}$ separately affect consolidated and labile odor memories. At $3 \mathrm{~h}$ after conditioning, performance of MTM is driven by two coexisting memories referred to as ASM or ARM directly reflecting their endurance of a post-acquisition anesthetic treatment. For experimental restrictions ASM is not accessible to direct measurement but is calculate by subtracting ARM performance (determined after cold amnestic treatment) from memory performance of an untreated group that is composed of ASM and ARM. $A, B$, rut $^{7}$ and $d n c^{1}$ mutants doubly dissociate between performance of consolidated ARM or labile ASM. While the $d n c^{7}$ mutant lacks ARM, the rut ${ }^{7}$ mutant lacks ASM. C, At the level of $3 \mathrm{~h} \mathrm{MTM}$, rut ${ }^{7}$ and $d n c^{7}$ mutants appear equally impaired in performance. $\boldsymbol{D}$, rut ${ }^{7}$ and $d n c^{1}$ mutants exhibit reduced, yet significant levels of STM (measured 3 min after training) that are abolished in double mutants. $E$, Perception of task relevant stimuli is not affected in the rut ${ }^{7}$, dnc ${ }^{1}$ double mutant. All data represent means $\pm \mathrm{SEM} ; N \geq 8$. Different characters indicate significant differences at the level of $p \leq 0.01$.

results allocated functionally different cAMP signals to the particular odor memories they support and suggest that the olfactory pathway holds two different types of memory independent of each other.

\section{Materials and Methods}

Fly care. Flies were raised at $24^{\circ} \mathrm{C}$ and $60 \%$ relative humidity with a $14 / 10$ h light-dark cycle on cornmeal-based food after the Würzburg receipt (Guo et al., 1996). Genetic crosses were performed according to standard procedures. Flies to be tested in behavioral experiments were transferred to fresh food vials for up to $48 \mathrm{~h}$ before the test. Genotypes including the Gal80 ${ }^{\text {ts }}$ repressor (McGuire et al., 2003) were raised at permissive temperature $\left(19^{\circ} \mathrm{C}\right)$ and placed at $30^{\circ} \mathrm{C}$ for $14-18 \mathrm{~h}$ to inactivate the $\mathrm{Gal} 80^{\text {ts }}$ repressor before testing associative memory performance. Experimental flies for dnc-RNAi knockdown were kept at $30^{\circ} \mathrm{C}$ to efficiently express the knockdown construct. All experiments were performed with 3- to 5-dold male F1 progeny of homozygous parental lines. Genetic lines used in this study were not outcrossed to a reference strain with a specific genetic background.

Behavioral experiments. Behavioral experiments were performed in dim red light at $70 \%$ relative humidity with isoamyl acetate (1:100 dilution in mineral oil presented in a $14 \mathrm{~mm}$ cup) and ethyl acetate (1:200 dilution in mineral oil presented in a $14 \mathrm{~mm}$ cup) serving as olfactory cues and $120 \mathrm{~V}$ AC current serving as behavioral reinforcer. Associative training was applied following the single-cycle training procedure described by Tully and Quinn (1985). For measuring performance of shortterm memory (STM), flies were tested immediately after the end of the training session; that is, exactly 3 min after onset of training. Performance of MTM and ARM was determined at $3 \mathrm{~h}$ after training and flies were transferred to neural containers without food for the resting period. For separation of consolidated ARM and labile ASM, two groups of flies were separately trained and one group was cooled in an ice-bath $\left(0^{\circ} \mathrm{C}\right)$ for $90 \mathrm{~s}$ at $2.5 \mathrm{~h}$ after training and tested for odor memory after $30 \mathrm{~min}$ of recovery (cold+ group). This treatment erases the labile ASM component; thus, performance of the cold + group is solely due to ARM. In contrast, ASM was calculated by subtracting the performance index of the cold+ group (which performed due to ARM) from performance of the cold - group, which performed due to ASM and ARM (Knapek et al., 2011). Nonassociative controls were performed as previously described (Schwaerzel et al., 2003). Calculation of behavioral indices was done as originally introduced by Tully and Quinn (1985).

Phosphodiesterase assays. Phosphodiesterase (PDE) assays were performed essentially as previously described (Day et al., 2005). Briefly, for each sample 10-15 heads were dissected from 7- to 9-d-old flies and homogenized in $50 \mu$ l of KHEM buffer ( $50 \mathrm{~mm} \mathrm{KCl,} 50$ mм HEPES, 1.94 mм $\mathrm{MgCl}_{2}, 10$ mм EGTA, 1 mm DTT, pH 7.4). Samples were cleared by centrifugation at $21,000 \times g$ at $4^{\circ} \mathrm{C}$ for $10 \mathrm{~min}$, supernatants were removed to a fresh tube, and the protein concentrations were determined by Bradford assay. The cAMP-PDE activity of the samples was determined at a $1 \mu \mathrm{M}$ final substrate concentration.

Generation of transgenic flies. dunce RNAi transgenic lines carry duncespecific sequence that will form hairpin loops when expressed under control of the upstream activator sequence (UAS) promoter. In brief, we generated RNAi constructs by cloning a 580 base pair fragment of dunce transcript D (base pairs 1617-2197) as an inverted repeat into the pWIZ vector. This fragment comprises five exons (exons 10-14 of transcript D) common to all dunce transcripts. The fragment was amplified using standard PCR methods with forward and reverse primers $5^{\prime}$-GCACTCTAGA GGTTTCGATGTAGAAAATGG-3' and 5'-GCACTCTAGAATATATT C-GGAAATCTGATTTCC-3', respectively, and sequentially cloned into the AvrII and NheI sites of pWIZ (Lee and Carthew, 2003). The resulting construct was used to transform w1118 embryos using standard Drosophila micro-injection techniques (BestGene Inc).

Statistical analysis. Comparisons were performed between multiple genotypes using one-way ANOVA with a post hoc test including Bonferroni correction for multiple comparisons. Significance is indicated by letters (a, b, c. . .) within the figures.

Analysis of Gal4 expression patterns. Whole-mount immunofluorescent preparation of the brain was described in a previous study (Thum et al., 2006). Micro-dissection was performed in Ringer's solution to remove cuticle and connective tissues. Brains were fixed in PBS (Sigma) containing $4 \%$ formaldehyde for $2 \mathrm{~h}$ on ice and subsequently rinsed with PBT three times at room temperature. Blocking of samples was performed in 5\% normal goat serum (Sigma) in PBT (PBS, BSA and Triton-X 100) for $2 \mathrm{~h}$; afterward brains were incubated with the primary antibodies in blocking solution at $4^{\circ} \mathrm{C}$ for $2 \mathrm{~d}$. The following primary antibodies were used: mouse monoclonal anti-synapsin 3C11 (1:10, Developmental Studies Hybridoma Bank at the University of Iowa) and rabbit polyclonal anti-GFP (1:1000, Invitrogen; A6455). Samples were washed three times for $10 \mathrm{~min}$ and once for $2 \mathrm{~h}$ with PBT and incubated with secondary antibodies in blocking solution at $4^{\circ} \mathrm{C}$ for $2 \mathrm{~d}$. Goat antirabbit Alexa Fluor 488 (1:200, Invitrogen) and goat anti-mouse Alexa Fluor 647 (1:200, Invitrogen) were used for detection of the primary antibodies. After five 10 min rinses with PBT, brains were mounted in Vectashield (Vector Labs) and confocal image stacks were taken with a Leica TCS SP 5 at $1 \mu \mathrm{m}$ steps with a $20 \times$ glycerol objective. The resulting image stacks were projected and analyzed with ImageJ (NIH) software; adjustments to contrast and brightness as well as rotations and organization of images were performed in Photoshop (Adobe). 


\section{Results}

rut-AC1 and dnc-PDE4 allocate cAMP signals to support of either ARM or ASM

Consolidated ARM and labile ASM are proportionate components of MTM that coexist at $3 \mathrm{~h}$ after aversive olfactory conditioning and can be separately quantified when cold-amnestic treatment is applied $30 \mathrm{~min}$ before testing $3 \mathrm{~h}$ odor memory (Tempel et al., 1983). When analyzing ARM and ASM, we discovered that the cAMP signaling mutant $d n c^{1}$ and $r u t^{1}$ separate between those memories: while ARM was abolished in the $d n c^{1}$ mutant (Fig. $1 A$ : $F_{(2,21)}=20.15, p<0.01$ ) those animals showed wild-type ASM and the reverse situation applied to the $r u t^{1}$ mutant (Fig. $\left.1 B: F_{(2,21)}=11.87, p<0.01\right)$. In this respect, the defect observed in $3 \mathrm{~h}$ MTM (Fig. 1C: $F_{(2,21)}=20.15, p<0.01$ ) was misleading to a certain extent, as neither the rut ${ }^{1}$ nor the $d n c^{1}$ mutant was impaired in all aspects of learning, but rather diametrically affected in one of two coexisting odor memories. Thus, one might ask how those particular signals might be distributed within the Drosophila brain to separately support different memories? The rut-dependent cAMP signals have been localized to mushroom body KCs by numerous studies (Davis, 2011). At the same time, a formal mapping of $d n c$-PDE4 function in support odor memory is still pending, although former studies have shown that Dnc protein is abundant and enriched in KCs (Nighorn et al., 1991).

In our approach to establish genetic tools for tissue-specific manipulation of dnc-PDE4, we first focused on impaired STM, the phenotype originally reported for $r u t^{l}$ and $d n c^{l}$ mutants (Dudai et al., 1976; Livingstone et al., 1984). STM was markedly reduced with a significant level of performance remaining unaffected in either mutant (Fig. 1D). This residual level, however, was abolished in a $d n c^{1}$, rut ${ }^{1}$ double mutant, $F_{(3,25)}=33.41, p<$ 0.01 . At the same time, the perception of task relevant stimuli was unaffected (Fig. $1 E$ ) excluding the trivial explanation that double mutants were anosmic or impaired in nociception. Rather, rut ${ }^{1}$ and $d n c^{1}$ mutants seem to separate labile ASM from consolidated $\mathrm{ARM}$ at $3 \mathrm{~h}$, as well as appropriate STM precursors immediately after training. We reasoned to use this STM impairment to establish tissue-specific manipulation of dnc-PDE4.

Establishing tissue-specific manipulation of dnc-PDE4 within the Drosophila brain

We used the Drosophila GAL4-UAS system (Brand and Perrimon, 1993) to modulate dnc-PDE4 activity by use of either RNA interference or genetic rescue, i.e., the ectopic expression of UAS$d n c+c D N A$ within an otherwise $d n c^{1}$ mutant background (Fig. 2). Either approach successfully modulated PDE activity when measured within head homogenates: neuronal knockdown of dnc-PDE4 diminished cAMP-specific PDE activity, whereas genetic rescue under control of the neuronal elav-Gal4 driver elevated $\mathrm{PDE}$ activity from reduced to wild-type levels (Fig. 2A: $\left.F_{(7,24)}=6.20, p<0.05\right)$. Genetic controls bearing either of the elements alone did not affect PDE activity. Consequences on aversive STM were as expected: while we noticed reduced performance of STM upon genetic knockdown, conversely, rescue of performance occurred after neuronal expression of UAS- $d n c+$ cDNA within an otherwise $d n c^{1}$ mutant background (Fig. $2 B$ : $\left.F_{(7,42)}=22.52, p<0.01\right)$. Finally, we used the temperaturesensitive Gal80 ${ }^{\text {ts }}$ repressor (McGuire et al., 2004) to restrict expression of the UAS-dnc+ rescue construct to the adult stage (Fig. 2C). As adult-specific expression sufficed for rescue of performance to wild-type levels, $F_{(5,27)}=18.32, p<0.01$, we concluded that dnc-PDE4 was not necessary for development of the
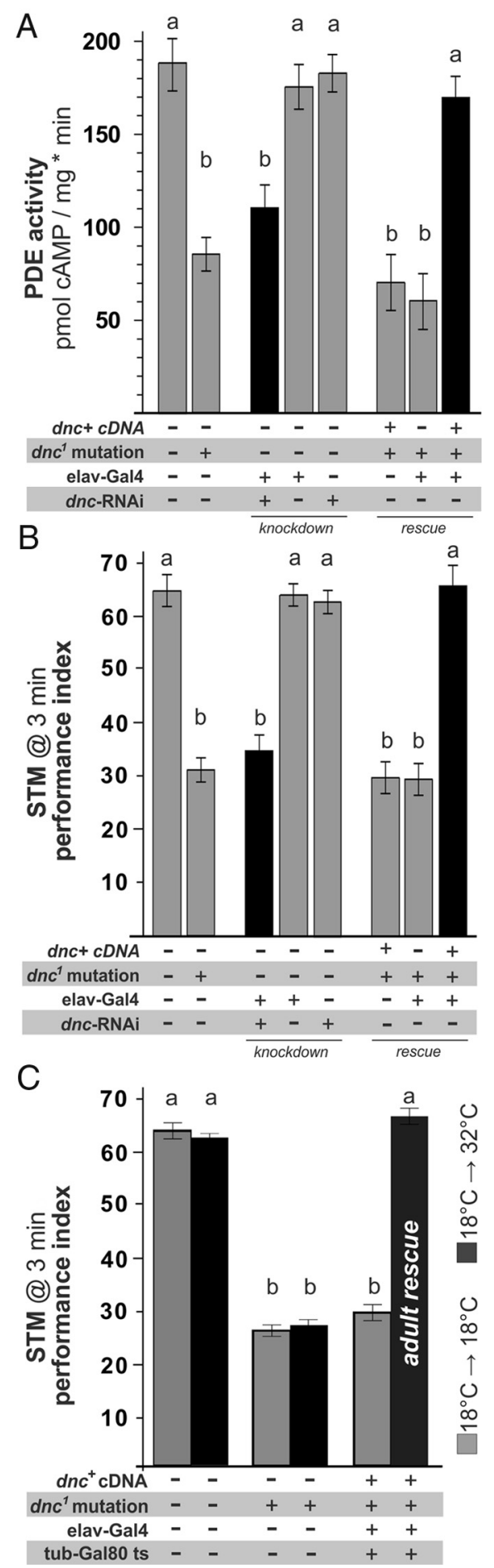

Figure 2. Specific modulation of dnc-PDE4 by genetic means. Transgenic expression of either $d n c$-specific double stranded RNAi or wild-type $d n c+c D N A$ within a $d n c^{1}$ mutant background modulates CAMP-specific PDE activity and correlates with performance of STM. $\boldsymbol{A}, d n c^{1}$ mutants exhibit reduced PDE activity within head homogenates, similar to animals that express the dnc-RNAi knockdown construct under control of the neuron-specific elav-Gal4 element. Conversely, PDE activity was rescued to wild-type levels when wild-type $d n c+c D N A$ was expressed in an otherwise $d n c^{1}$ mutant background. Genetic controls did not affect PDE activity. $\boldsymbol{B}$, Performance of odor memory correlated with dnc-PDE4 activity. Neuron-specific knockdown of dnc-PDE4 activity affected STM. Conversely, genetic rescue of $d n c^{1}$ mutants restored memory performance to wild-type levels. Genetic controls did not affect memory performance. $\boldsymbol{C}$, Expressing $\mathrm{dnc}+\mathrm{CDNA}$ at the adult stage by use of the temperature-sensitive Gal $80^{\text {ts }}$ repressor sufficed for rescue of memory performance. All data represent means \pm SEM. Sample sizes for PDE activity assays were $N \geq 3$ and for behavioral assays $N \geq 8$. Different characters indicate statistical significances at the level of $p<0.01$. 


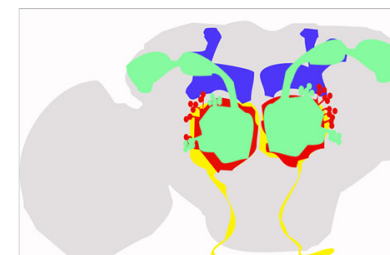

A

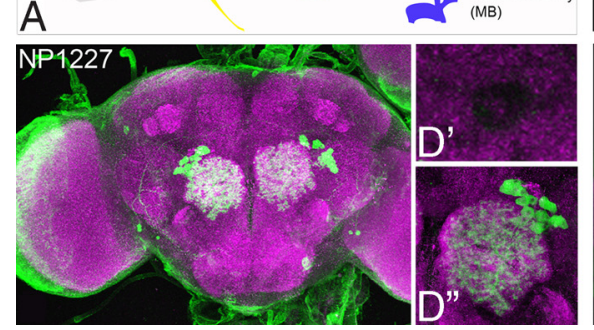

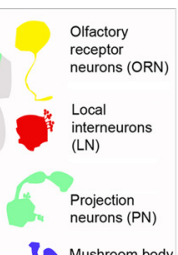

Mush
(MB)
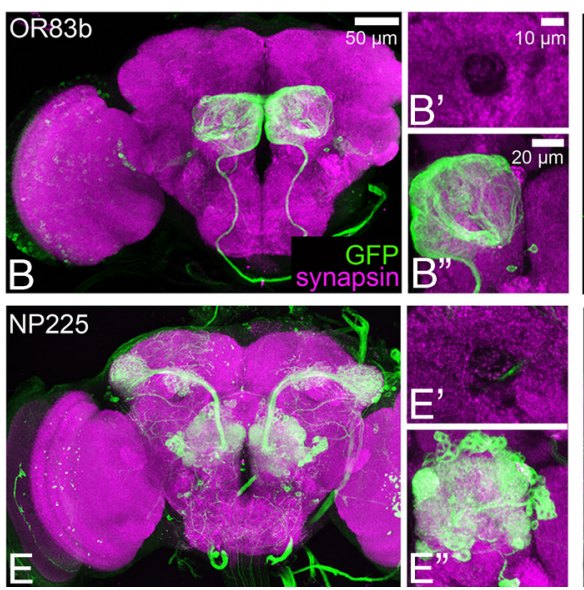
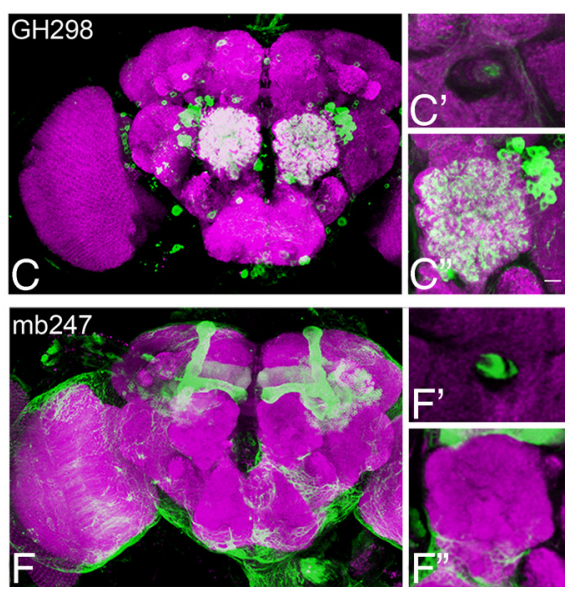

Figure 3. Immunohistochemical analysis of Gal4 drivers targeting distinct stages of the olfactory pathway. Several Gal4 lines specific for different layers of the olfactory pathway were crossed to UAS-mCD8::GFP and double-stained by anti-GFP (green) and anti-synapsin (magenta) as a neuronal marker. Each main panels show a frontal view of $z$-projections of $1 \mu \mathrm{m}$ sections revealing the expression pattern of the driver line in the brain. For the insets, on the upper right side a single section focusing on the peduncle is shown, followed by a single section of the antennal lobe underneath. A, Schematic representation of the olfactory pathway: first-order ORNs convey odor information to the antennal lobe, which is innervated by GABAergic and cholinergic local interneurons. Second order PNs distribute the olfactory information to higher brain centers, MB calyx and lateral horn. Mushroom body intrinsic neurons, the Kenyon cells represent third-order olfactory neurons and are presumed site of a memory trace for aversive associative odor memory. $\boldsymbol{B}, 0 \mathrm{r} 83 \mathrm{~b}$ Gal4 shows a specific staining for a large set of ORNs, but lacks expression in the MB. $\boldsymbol{C}$, GH298 shows staining mainly restricted to a set of local interneurons, limited MB expression is also seen at the center of the penduncle. D, NP1127 shows a specific staining for a set of local interneurons. $\boldsymbol{E}$, NP225 specifically labels approximately two-thirds of the PNs. F, mb247 Gal4 drives GFP expression particularly in a comprehensive set of the intrinsic MB Kenyon cells.

CNS but rather acutely required for the associative process in adults, consistent with previous work (Dauwalder and Davis, 1995). With a genetic toolbox successfully established we proceeded to define neuronal correlates of dnc-PDE4 function for support of odor memory.

\section{dnc-PDE4 supports odor memory within antennal lobes and mushroom bodies}

Olfactory information about the surrounding environment is internally represented by neural activity within the olfactory pathway of the brain. In Drosophila, this pathway follows a stereotyped organization analogous to the mammalian olfactory bulb (Vosshall and Stocker, 2007): airborne chemicals result in activation of olfactory receptor neurons (ORNs) that project their axons to the ALs. At this level, information is computed within the layers of LNs and projection neurons (PNs) and conveyed to higher olfactory centers, i.e., the lateral horn and the MBs (Sachse et al., 2007; Aso et al., 2009; Chou et al., 2010). To test which neuronal populations of this circuit require dnc-PDE4 we used a set of Gal4 lines, each driving expression in a given neural layer, i.e., OR83b drives expression in ORNs, GH298 and NP1227 in GABAergic LNs of the ALs, NP225 in PNs and mb247 in MBs (see Fig. 3 for expression patterns).

First, we targeted the RNAi-knockdown construct to individual neuron populations to identify those that require dnc-PDE4 for STM performance (Fig. 4A). Knockdown at the level of Gal4 lines GH298 or NP1227 that mark GABAergic LNs of the ALs decreased memory performance, $F_{(6,44)}=30.56, p<0.01$. Surprisingly, knockdown at the level of ORNs, PNs, or MBs was without effect. Next, we used tissue-specific dunce rescue within individual neuron populations, including OR83b, GH298, NP1227, NP225, and mb247, but failed to restore memory performance regardless of which stage of the olfactory pathway was targeted, $F_{(6,40)}=25.66, p<0.01$ (Fig. $4 B$ ). We then went for combinations of two drivers. Of note, a successful rescue required simultaneous expression of UAS-dnc + within LNs of the antennal lobes and KCs of the mushroom bodies. This combination was achieved by two specific combinations of Gal4 lines, i.e., mb247 with GH298, or mb247 with the LN-Gal4 driver NP1227, which produced partial but significant rescue, $F_{(6,44)}=39.78, p<$ 0.01 (Fig. $4 C$ ). Thus, our results suggest that dnc-PDE4 function is needed in two "stages" of the olfactory pathway, LNs and KCs. Moreover, KCs and LNs supported nonredundant functions, as revealed by the failure of separate rescue.

LN cell bodies are located in two clusters, i.e., one cluster located dorsolateral to the antennal lobe and a separate cluster more ventrally (Chou et al., 2010). Our results favored dorsolateral, but not ventral, LNs as critical localization for dnc-PDE4 in support of aversive odor memory. First, the Gal4 expression patterns revealed by the dunce rescue include two lines marking dorsolateral GABAergic LNs, i.e., GH298-Gal4, which marked 28 LNs, and NP1227-Gal4, which marked $\sim 18$ LNs (Sachse et al., 2007; Chou et al., 2010). Second, OK107-Gal4 marked 103 LNs of the ventral cluster (Chou et al., 2010) but failed to rescue odor memory (Fig. 5B). Markedly, the OK107 pattern includes $\sim 1900$ KCs (Aso et al., 2009) and rescued memory performance when UAS-dnc + cDNA was simultaneously expressed within the GH298 pattern to include dorsolateral LNs (Fig. 5B). Third, knockdown of dnc-PDE4 with OK107 did not affect odor learning (PI $=68.2 \pm 2.4 ; N=8$ ) further supporting the conclusion that Dnc function within ventral LNs was dispensable for odor learning. It was striking that dnc-RNAi did not affect odor memory when expressed in KCs. We speculated that restrictions in expression of the Gal4 lines might be causal for this outcome, i.e., mb247 and OK107 mark comprehensive fractions of the mushroom body but not the entire set of $>2000 \mathrm{KCs}$ (Technau, 1984), thus retaining a reasonable number of KCs with Dnc function in either combination.

Together, these results relate dnc-PDE4 function in GABAergic LNs to KCs for support of the dnc-dependent fraction of STM.

\section{dnc-PDE4 and rut-AC1 support memory within different KC circuits}

While KCs have long been recognized as neuronal correlate of rut-AC1, the presumed site of odor-shock convergence support- 

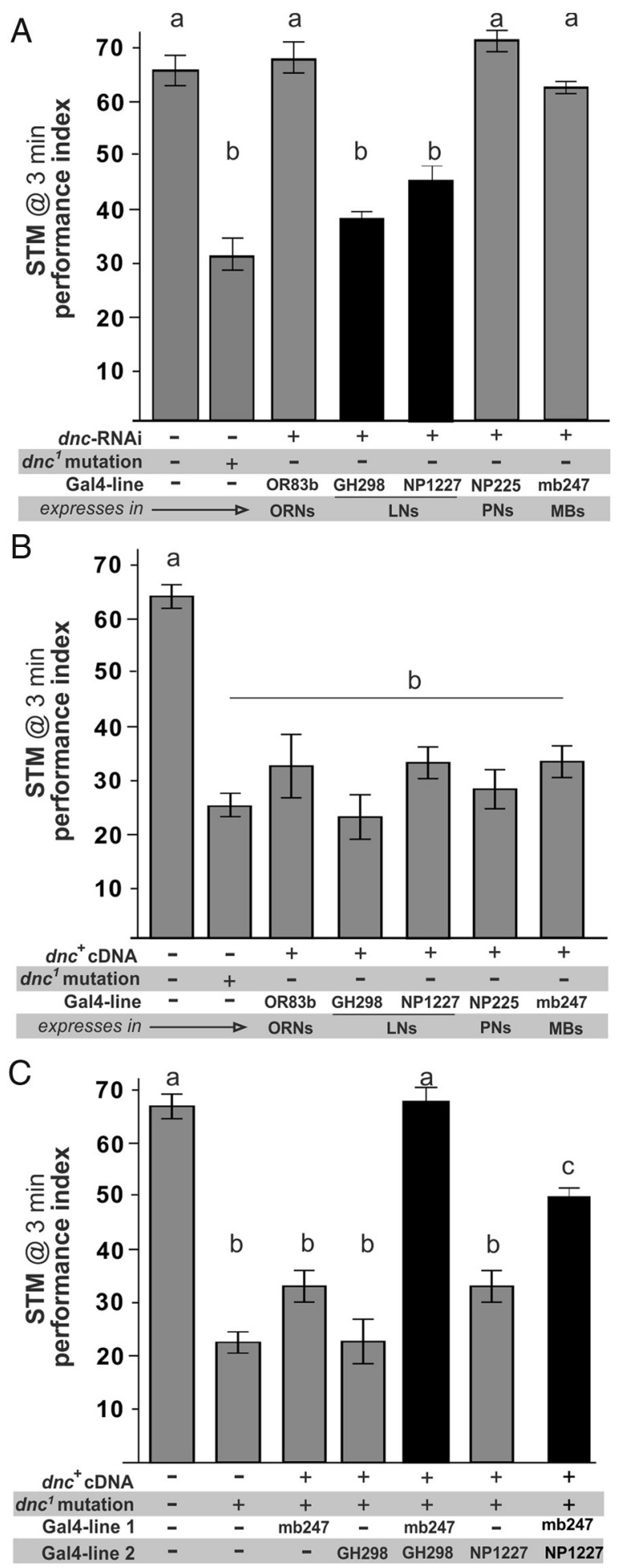

Figure 4. Local neurons of the antennal lobes and Kenyon cells of the mushroom bodies are cellular correlates of dnc-PDE4 in support of odor memory. Knockdown or rescue of dnc function was used to define its neuronal correlates for support of STM. A, Targeting dnc-RNAi to distinct stages of the olfactory pathway affected memory performance at the level of GABAergic LNs marked in GH298 or NP1227. B, Conversely, dnc rescue at individual stages of the olfactory pathway did not improve performance. $C$, Successful rescue required $\mathrm{dnc}+\mathrm{cDNA}$ under the combined control of GH298 and mb247, marking 28 GABAergic LNs in addition to $1600 \mathrm{KCS}$. The alternative combination of NP1227 marked 18 GABAergic LNs and partially rescued memory performance when combined with the mb247 pattern. All data represent means \pm SEM; $N \geq 8$. Different characters indicate significant differences at the level of $p \leq 0.01$. ing ASM, our analysis identified KCs as neuronal localization of dnc-PDE4 function. Thus, two different enzymes involved in regulation of cellular cAMP levels localize to MBs directly raising questions how dnc-PDE4 and rut-AC1 are organized at the level of KC populations? To address that issue we used genetic rescue of either mutant in a site-by-site comparison focusing on Gal4 lines expressing within different lobe systems of the mushroom bodies, i.e., $\alpha / \beta$, prime, or $\gamma$ lobes (Aso et al., 2009).

While rut ${ }^{1}$ mutants exhibited approximately one-third of wild-type performance, expression of UAS-rut+ cDNA under control of OK107 or mb247 sufficed for restoring STM performance to wild-type levels, $F_{(8,58)}=42.33, p<0.01$ (Fig. $5 A$ ). In contrast, more refined Gal4 drivers that restricted expression to particular MB lobe systems failed to rescue, i.e., when marking the $\alpha / \beta$ lobes with $17 \mathrm{~d}-\mathrm{Gal} 4$, the $\gamma$ lobes with NP1131-Gal4 or the prime lobes with c305a- or c320-Gal4, respectively. These data supported previous findings that placed rut-AC1 function within KCs of the $\alpha / \beta$ or $\gamma$ lobes at a central position for support of STM (Zars et al., 2000; McGuire et al., 2004; Akalal et al., 2006; Blum et al., 2009).

In the case of $d n c^{l}$ mutants our experiments identified redundant $\mathrm{KC}$ circuits that, in combination with LNs, were able to restore STM when rescued within either $\alpha / \beta, \gamma$ or even prime lobes, $F_{(14,88)}=43.19, p<0.01$ (Fig. $5 B$ ). As $d n c^{1}$ has been classified as a hypomorph by means of cAMP-specific PDE activity measured in head homogenates (Davis, 1996), we cannot exclude the possibility that much more refined sets of neurons might suffice dnc-PDE4 for support of STM.

\section{Different key positions of the olfactory pathway are modified} for supporting ARM or ASM

After mapping the neuronal distribution of where either rut-AC1 or dnc-PDE4 supported STM, we next addressed which neurons required those enzymes to support either ARM or ASM at $3 \mathrm{~h}$ after conditioning. According to the neuronal requirements for STM support, we used the same Gal4 lines and showed that consolidated ARM and labile ASM both required the cAMPmodulating enzymes in identical neuronal subtypes that were identified to facilitate appropriate STM precursors: the ASM impairment of $r u t^{1}$ mutants was restored by rescue within KCs of $\alpha / \beta$ and $\gamma$ lobes, $F_{(4,27)}=38.67, p<0.01$ (Fig. $6 A$ ), while the restoration of ARM impairment required dnc-PDE4 within LNs of the antennal lobes and KCs of either lobe system, $F_{(7,46)}=$ 23.94, $p<0.01$ (Fig. 6B). Within a reciprocal approach we showed that expression of the $d n c$-RNAi construct specifically affected ARM, but not ASM, when expressed in a pan neuronal fashion under control of the elav-Gal4 line, $F_{(4,32)}=17.02, p<$ 0.01 (Fig. 6C). More restricted expression within LNs by use of the GH298-Gal4 line disrupted ARM, while expression in the KC-specific pattern of mb247-Gal4 did not. Thus, neither STM nor ARM were affected by RNAi expressed under control of a KC-specific Gal4 driver.

\section{Discussion}

Here, we showed that consolidated ARM is separated from labile ASM by (1) the neurons of the olfactory pathway that require cAMP signaling, and (2) the particular enzymes involved in regulation of appropriate cAMP signals. We showed that rut-AC1 is required for labile ASM simultaneously within KCs of $\alpha \beta$ and $\gamma$ type, and dnc-PDE4 within KCs and antennal lobe LNs for support of ARM. Given the assumption that those distinct cAMP signals link to regulation of synaptic plasticity, our results suggest 

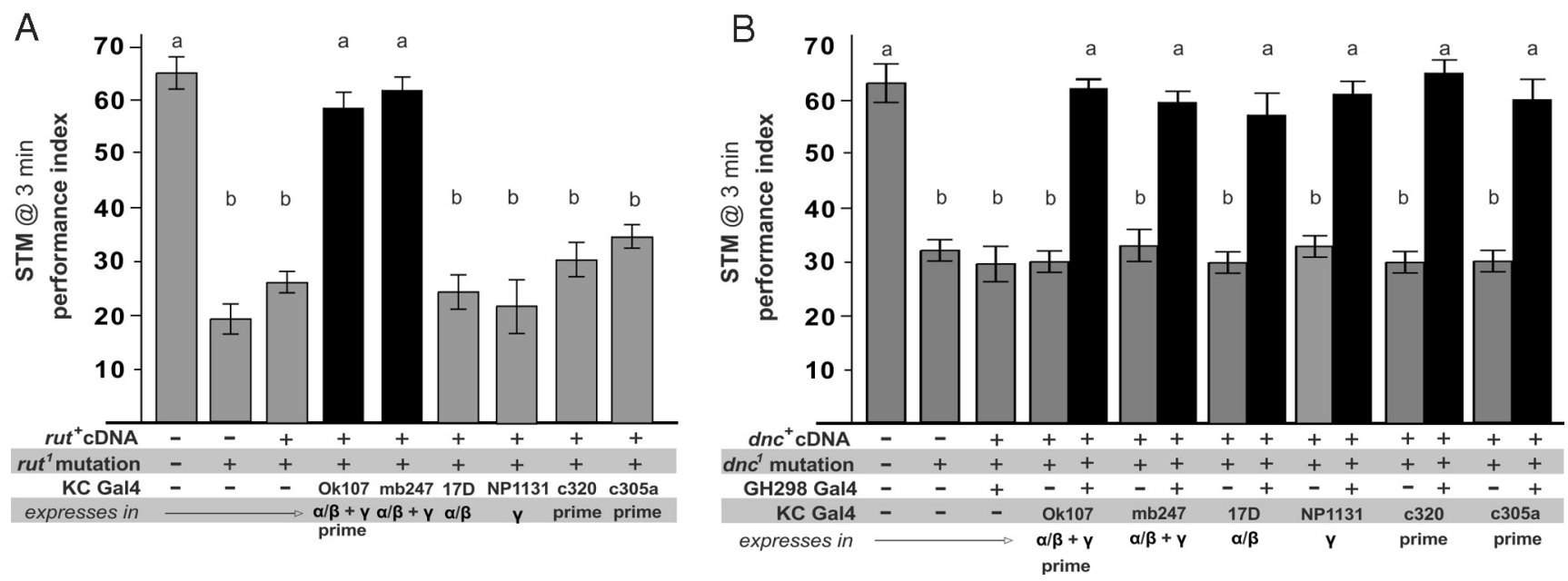

Figure 5. rut-AC1 and dnc-PDE4 support STM within different mushroom body circuits. Genetic rescue of either rut ${ }^{1}$ or $d n c^{1}$ mutants was performed site-by-site for STM. $A$, Rut rescue required combined expression of UAS-rut + CDNA within KCs of the $\alpha / \beta$ and $\gamma$ lobes, as this represents the cut-set of expression from 0K107- and mb247-Gal4. Restricting the rescue to $\alpha / \beta, \gamma$ or prime lobes separately, did not rescue. $\boldsymbol{B}$, dnc rescue required combined expression of UAS-dnc + cDNA within GABAergic LNs marked by GH298 and any type of KCs, i.e., $\alpha / \beta, \gamma$ or prime lobes. All data represent means $\pm \mathrm{SEM} ; N \geq 8$. Different characters indicate significant differences at the level of $p \leq 0.01$.

A

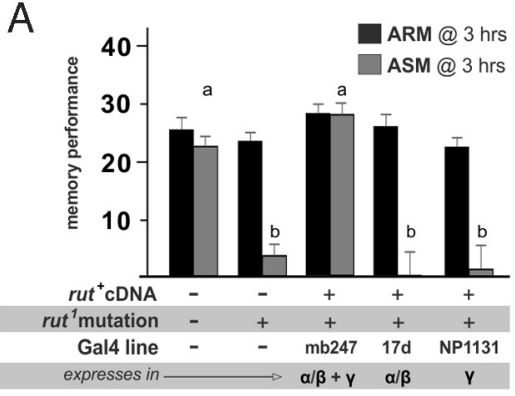

B

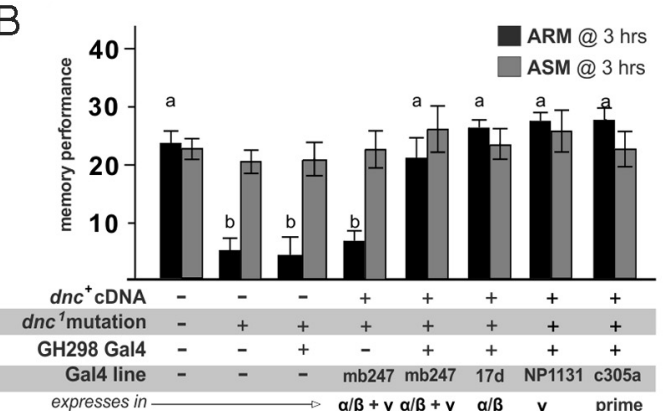

C

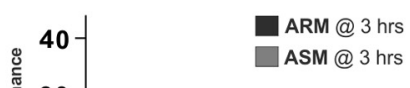
ARM @ 3 hrs
ASM @ 3 hrs

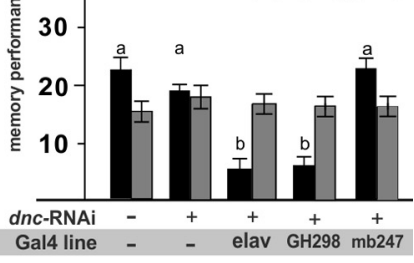

Figure 6. Two functionally distinct cAMP signals support ARM and ASM within different neuronal circuits. ARM and ASM are supported by different neuronal correlates of cAMP signaling. $\boldsymbol{A}$, rut-AC1-dependent CAMP signals are simultaneously required within KCs of the $\alpha / \beta$ and $\gamma$ neurons to support performance of ASM, while ARM was unaffected. $B$, Performance of ARM requires dnc-PDE4 function within GABAergic LNs of the antennal lobes in combination with any type of KCs. Within mushroom bodies there is functional redundancy between KCs of the $\alpha / \beta$, prime or $\gamma$ systems. The performance of ASM was unaffected. C, In a reciprocal approach the dnc-RNAi construct disrupted ARM when expressed under control of elav-Gal4 or GH298-Gal4, but not with mb247-Gal4. All data represent means \pm SEM; $N \geq 8$. Different characters indicate significant differences at the level of $p \leq 0.01$.

that labile ASM and consolidated ARM are separately encoded within different neuron populations of the olfactory pathway.

\section{rut-dependent plasticity supports labile ASM in KCs of the $\boldsymbol{\alpha} \boldsymbol{\beta}$ and $\boldsymbol{\gamma}$ type}

Drosophila olfactory conditioning requires temporal contingency between the olfactory CS and reinforcing electric shock, the US (Tanimoto et al., 2004). One anatomical correlate of CS/US convergence within the Drosophila brain is mushroom body KCs, higher order olfactory neurons, where dopaminergic neurons provide US-related impulses onto the olfactory pathway (Aso et al., 2010,2012). At the molecular level, type 1 adenylyl cyclase acts as contingency detector for $\mathrm{Ca}^{2+} /$ calmodulin and G-protein signals and accordingly, rut-AC1 is supposed to integrate CS-related $\mathrm{Ca}^{2+}$ signals with US-related G-protein signals at the level of KCs (Tomchik and Davis, 2009; Gervasi et al., 2010). Consistent with this hypothesis the PKA signaling cascade and further downstream effectors of synaptic efficacy, like synapsin and tomosyn, localize to KCs (Schwaerzel et al., 2007; Knapek et al., 2010; Chen et al., 2011; Michels et al., 2011).

By means of the $r u t^{l}$ rescue, our data indicate a logic interconnection between KCs of the different lobe systems. Especially, KCs of the $\alpha / \beta$ and $\gamma$ type are simultaneously required for rescue of labile ASM (and its STM precursor). This result is contradictive to the previous finding that KCs of either $\alpha / \beta$ or $\gamma$ type rescued within a rut ${ }^{2080}$ background (Zars et al., 2000; McGuire et al., 2003; Akalal et al., 2006). We suggest that choice of the particular rut-allele is affecting the outcome of appropriate rescue experiments due to residual AC1 activity within the commonly used rut ${ }^{2080}$ background (Pan et al., 2009). In contrast to rut $^{2080}$, rut $^{1}$ mutants bear a point mutation within the catalytic site of $\mathrm{ACl}$ and abolish $\mathrm{Ca}^{2+}$-dependent cyclase activity, thus formally classify as functional null allele for assumed CS/US convergence detection (Pan et al., 2009).

ASM is not sufficiently supported by rut-dependent plasticity of KCs but rather requires prolonged neural activity as revealed by the retrograde amnesia induced after amnestic cooling. Particularly, the prime lobe KCs, as well as the DPM neuron, is essentially required to stabilize ASM as it maturates over time by release of the amnesiac neuropeptide (Waddell et al., 2000; Yu et al., 2005; Krashes et al., 2007). Direct electrical connections between DPM and two anterior paired lateral (APL) neurons further recruit the two GABA-positive APL neurons, which provide negative feedback to modulate the representation of odor impulses at the level of KCs (Liu and Davis, 2009; Liu et al., 2009; Papadopoulou et al., 2011; Wu et al., 2011). Downstream of this 
A

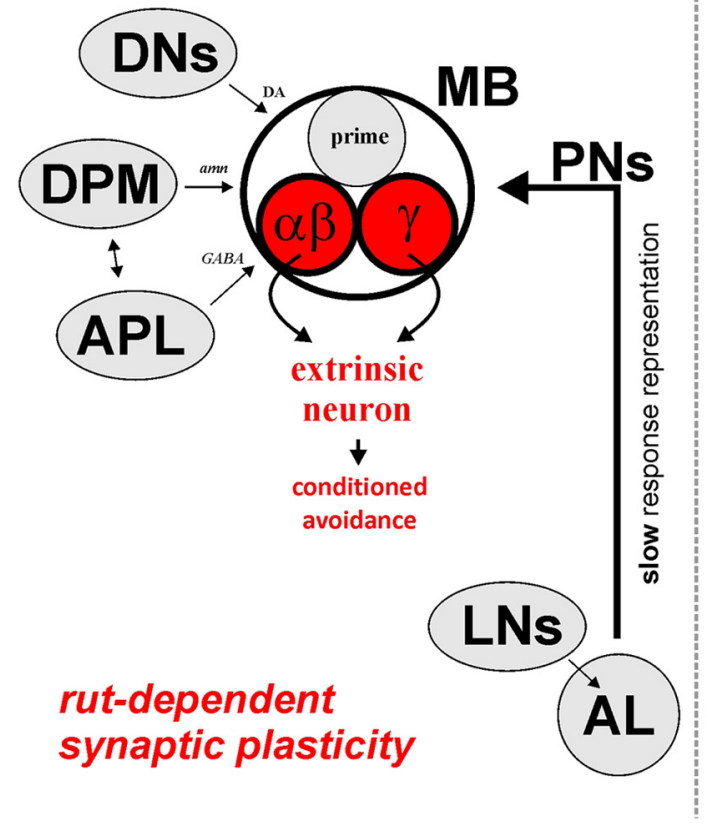

stable ARM

B

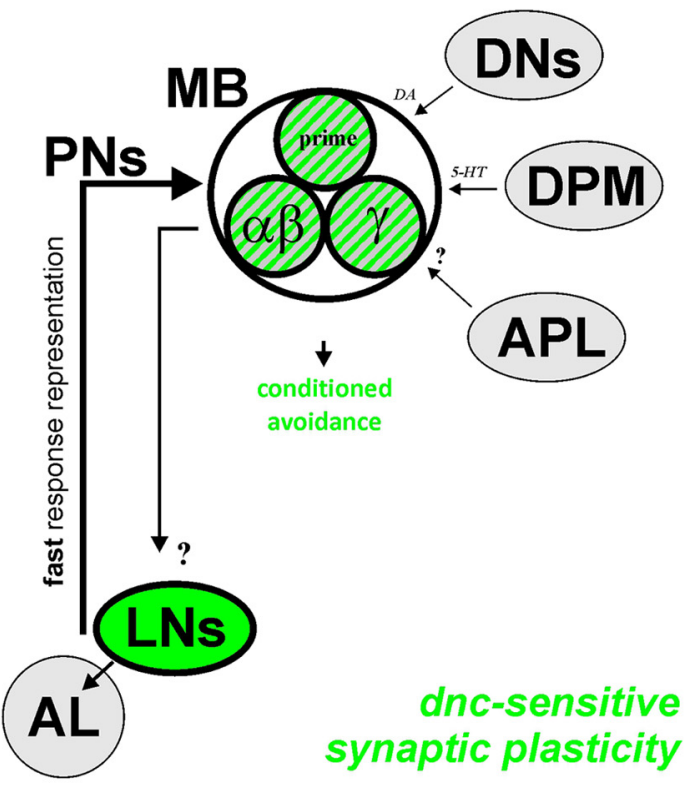

Figure 7. Distinct distribution of cAMP-dependent plasticity within the olfactory pathway separates consolidated ARM and labile ASM.A, CAMP signals derived from rut-AC1 (red) localize to KCs of the $\alpha / \beta$ and $\gamma$ type to support labile ASM (B). dnc1-sensitive CAMP signals localize to KCs of either the $\alpha / \beta$, $\gamma$ or prime type (green-gray) and LNs of the ALs (green). It remains to be determined if the KC layer receives differently computed odor representations from the AL. DNs, Dopaminergic neurons; DPM, dorsal paired medial neuron; DA, dopamine; 5-HT, serotonin; amn, amnesiac peptide.

KC-DPM-APL network that is engaged during dynamic modulation of ASM over time, the labile memory is encoded by rutdependent plasticity within KCs of the $\alpha / \beta$ and $\gamma$ type (Fig. 7A). From here, conditioned avoidance is supposed to be mediated by mushroom body extrinsic neurons (Séjourné et al., 2011). Those would be in an adequate anatomical position to detect and permute the convergent plasticity within KCs of the $\alpha / \beta$ and $\gamma$ type into behavior. Such system is reminiscent of a filter tuned to avoid false-positive outcomes that might be provided by plasticity within either $\alpha / \beta$ or $\gamma$ type KCs alone. Given the aversive nature of the memory response that inevitably would result in abstinence of rare natural resources, a precise tuning of the ASM memory system seems appropriate.

\section{ARM engages the olfactory pathway in a different way than ASM}

On the molecular level, the cAMP/PKA signaling pathway is essential within KCs for support of consolidated ARM, and ARMspecific dopaminergic neurons convey US-related impulses onto the olfactory pathway at the level of KCs (Yamazaki et al., 2010; Plaçais et al., 2012). Thus, ARM and its appropriate STM memory precursor seem to be encoded within the same circuitry than labile ASM, but in a way that sustains amnestic cooling. Moreover, our data show that both memories are encoded in parallel and that $d n c^{1}$-sensitive cAMP signals serve a different function from rut-dependent detection of CS/US convergence. Even more, dnc-PDE4 affects GABAergic LNs of the ALs, a central computation unit of the olfactory pathway, without affecting performance of rut-dependent ASM. We suggest that this double dissociation of cAMP signals is informative for how memory is processed within the olfactory pathway.

Synaptic plasticity at the level of the ALs has been associated with olfactory memory in the honeybee (Faber et al.,
1999; Müller, 2000; Fernandez et al., 2009), while in Drosophila the major focus has been on MBs. However, Yu and Davis (2004) reported experience-dependent plasticity at the level of the ALs in a Drosophila imaging preparation that resembles associative odor learning. Experience-dependent plasticity of Drosophila courtship has also been reported to require ALs (McBride et al., 1999; Hallem and Carlson, 2004), suggesting conserved functions for associative memory formation within the insect olfactory pathway.

While olfactory information is computed, its neuronal representation dramatically changes as impulses pass through the different layers of the olfactory pathway: at the level of ALs, there is a compact representation that is transformed to a sparse representation at the level of KCs (Jortner et al., 2007; Turner et al., 2008; Papadopoulou et al., 2011). This transformation is critically dependent on GABAergic inhibition by antennal lobe LNs that mediate inhibitory feedback onto PNs (Wilson et al., 2004; Wilson and Laurent, 2005). It is the stage of LNs where dnc-PDE4 is required for support of consolidated ARM and we speculate that $d n c^{1}$-sensitive cAMP signals interfere with regulation of GABAergic feedback inhibition. Dnc mutants exhibit persistently activated $\mathrm{K}^{+}$channels that mimic synaptic potentiation at the larval NMJ (Delgado et al., 1991; Zhong and Wu, 1991). It is thus possible that facilitated GABAergic inhibition within $d n c^{1} \mathrm{mu}-$ tants interferes with the odor representation at the level of PNsand thus with impulses that are transposed to the MBs. The PN response, however, holds a temporal dynamic as GABA hyperpolarizes PNs via two different conductances that shape odor responses on different time scales (Wilson and Laurent, 2005). It is tempting to speculate that $\mathrm{GABA}_{\mathrm{A}}$-sensitive, fast $\mathrm{PN}$ responses are misrelated in the $d n c^{1}$ mutant and that KCs fail to represent the full dynamic spectrum of the olfactory CS. Intriguingly, the Drosophila Bruchpilot protein is required within KCs to support 
ARM but not ASM, in line with its proposed function to facilitate efficient vesicle release at low-frequency stimulation (Knapek et al., 2011). We hypothesize that KCs process fast and slow representations of the olfactory CS differently (Fig. 7B).

ARM requires convergent function of dnc-PDE4 within LNs of the ALs and KCs of the MBs. At the level of MBs, however its requirement is divergently distributed between KCs of the $\alpha / \beta, \gamma$ and prime lobes, thus an opposite requirement than convergent rut-AC1 function. We speculate that $d n c^{1}$-sensitive cAMP signals might be involved in regulation of a KC-LN feedback loop, the existence of which is well supported by physiological data. However, its anatomical requirements remain unidentified (Hu et al., 2010). Redundant top-down modulation of antennal lobe function by feedback from either lobe system might be advantageous given that odors are represented in parallel within the different lobe systems (Turner et al., 2008). In this scenario, $d n c^{l}$-sensitive plasticity at the level of KCs would not interfere with rutdependent encoding of ASM but specifically affect the computation of CS-related impulses feeding into ARM formation.

\section{Genetic handles to aid in dissection of the cAMP-signaling network}

By means of cellular cAMP levels the $d n c^{l}$ allele classifies as weak hypomorph as judged from the twofold increased in $d n c^{l} \mathrm{mu}-$ tants and eightfold increased in the strong $d n c^{M L}$ allele (Davis, 1996). Regardless of cellular cAMP levels, however those two mutants exhibit equally impaired odor learning (Dauwalder and Davis, 1995), suggesting that overall cellular cAMP levels and impaired odor learning are functionally independent. From a geneticist's perspective, the $d n c$ locus is a large locus ( $>148 \mathrm{~kb}$ ) encoding 14 transcripts that all share a unique PDE domain (Qiu and Davis, 1993; Qiu et al., 1991) that is targeted by the UAS$\mathrm{RNAi}^{\mathrm{dnc}}$ construct. The UAS-dnc + rescue construct (Cheung et al., 1999) contained a short cDNA that codes for the PDE domain but lack the specific N-terminal domains of the native transcripts (Qiu and Davis, 1993). So more refined genetic tools are desirable if one aims to allocate particular functions to specific transcripts.

From a biochemical perspective, $d n c$ and rut mutants affect very different aspects of cellular cAMP signaling; while rut $t^{1} \mathrm{mu}$ tants specifically lack a $\mathrm{Ca}^{2+}$-dependent cAMP signal, $d n c^{1}$ affects the breakdown of cAMP and mutants have elevated levels of second messenger (Davis, 1996) which will affect downstream signals, e.g., PKA or EPAC. Moreover, multiple other PDEs and ACs are known within the Drosophila genome (Maas et al., 2005; Day et al., 2008), with their functional implication in associative odor learning still undetermined. Thus it appears that cellular cAMP signaling involved in aversive odor learning is more complex that originally thought.

\section{References}

Abrams TW, Kandel ER (1988) Is contiguity detection in classical conditioning a system or a cellular property? Learning in Aplysia suggests a possible molecular site. Trends Neurosci 11:128-135. CrossRef Medline

Akalal DB, Wilson CF, Zong L, Tanaka NK, Ito K, Davis RL (2006) Roles for Drosophila mushroom body neurons in olfactory learning and memory. Learn Mem 13:659-668. CrossRef Medline

Aso Y, Grübel K, Busch S, Friedrich AB, Siwanowicz I, Tanimoto H (2009) The mushroom body of adult Drosophila characterized by GAL4 drivers. J Neurogenet 23:156-172. CrossRef Medline

Aso Y, Siwanowicz I, Bräcker L, Ito K, Kitamoto T, Tanimoto H (2010) Specific dopaminergic neurons for the formation of labile aversive memory. Curr Biol 20:1445-1451. CrossRef Medline

Aso Y, Herb A, Ogueta M, Siwanowicz I, Templier T, Friedrich AB, Ito K, Scholz H, Tanimoto H (2012) Three dopamine pathways induce aver- sive odor memories with different stability. PLoS Genet 8:e1002768. CrossRef Medline

Blum AL, Li W, Cressy M, Dubnau J (2009) Short- and long-term memory in Drosophila require cAMP signaling in distinct neuron types. Curr Biol 19:1341-1350. CrossRef Medline

Brand AH, Perrimon N (1993) Targeted gene expression as a means of altering cell fates and generating dominant phenotypes. Development 118: 401-415. Medline

Chen K, Richlitzki A, Featherstone DE, Schwärzel M, Richmond JE (2011) Tomosyn-dependent regulation of synaptic transmission is required for a late phase of associative odor memory. Proc Natl Acad Sci U S A 108: 18482-18487. CrossRef Medline

Cheung US, Shayan AJ, Boulianne GL, Atwood HL (1999) Drosophila larval neuromuscular junction's responses to reduction of cAMP in the nervous system. J Neurobiol 40:1-13. CrossRef Medline

Chou YH, Spletter ML, Yaksi E, Leong JC, Wilson RI, Luo L (2010) Diversity and wiring variability of olfactory local interneurons in the Drosophila antennal lobe. Nat Neurosci 13:439-449. CrossRef Medline

Dauwalder B, Davis RL (1995) Conditional rescue of the dunce learning/ memory and female fertility defects with Drosophila or rat transgenes. J Neurosci 15:3490-3499. Medline

Davis RL (1996) Physiology and biochemistry of Drosophila learning mutants. Physiol Rev 76:299-317. Medline

Davis RL (2011) Traces of Drosophila memory. Neuron 70:8-19. CrossRef Medline

Day JP, Dow JA, Houslay MD, Davies SA (2005) Cyclic nucleotide phosphodiesterases in Drosophila melanogaster. Biochem J 388:333-342. CrossRef Medline

Day JP, Cleghon V, Houslay MD, Davies SA (2008) Regulation of a Drosophila melanogaster cGMP-specific phosphodiesterase by prenylation and interaction with a prenyl-binding protein. Biochem J 414:363-374. CrossRef Medline

Delgado R, Hidalgo P, Diaz F, Latorre R, Labarca P (1991) A cyclic AMPactivated $\mathrm{K}+$ channel in Drosophila larval muscle is persistently activated in dunce. Proc Natl Acad Sci U S A 88:557-560. CrossRef Medline

Dudai Y, Jan YN, Byers D, Quinn WG, Benzer S (1976) dunce, a mutant of Drosophila deficient in learning. Proc Natl Acad Sci U S A 73:1684-1688. CrossRef Medline

Faber T, Joerges J, Menzel R (1999) Associative learning modifies neural representations of odors in the insect brain. Nat Neurosci 2:74-78. CrossRef Medline

Fernandez PC, Locatelli FF, Person-Rennell N, Deleo G, Smith BH (2009) Associative conditioning tunes transient dynamics of early olfactory processing. J Neurosci 29:10191-10202. CrossRef Medline

Gervasi N, Tchénio P, Preat T (2010) PKA dynamics in a Drosophila learning center: coincidence detection by rutabaga adenylyl cyclase and spatial regulation by dunce phosphodiesterase. Neuron 65:516-529. CrossRef Medline

Guo A, Li L, Xia SZ, Feng CH, Wolf R, Heisenberg M (1996) Conditioned visual flight orientation in Drosophila: dependence on age, practice, and diet. Learn Mem 3:49-59. CrossRef Medline

Hallem EA, Carlson JR (2004) The spatial code for odors is changed by conditioning. Neuron 42:359-361. CrossRef Medline

Horiuchi J, Yamazaki D, Naganos S, Aigaki T, Saitoe M (2008) Protein kinase A inhibits a consolidated form of memory in Drosophila. Proc Natl Acad Sci U S A 105:20976-20981. CrossRef Medline

Houslay MD (2010) Underpinning compartmentalised cAMP signalling through targeted cAMP breakdown. Trends Biochem Sci 35:91-100. CrossRef Medline

Hu A, Zhang W, Wang Z (2010) Functional feedback from mushroom bodies to antennal lobes in the Drosophila olfactory pathway. Proc Natl Acad Sci U S A 107:10262-10267. CrossRef Medline

Isabel G, Pascual A, Preat T (2004) Exclusive consolidated memory phases in Drosophila. Science 304:1024-1027. CrossRef Medline

Jortner RA, Farivar SS, Laurent G (2007) A simple connectivity scheme for sparse coding in an olfactory system. J Neurosci 27:1659-1669. CrossRef Medline

Knapek S, Gerber B, Tanimoto H (2010) Synapsin is selectively required for anesthesia-sensitive memory. Learn Mem 17:76-79. CrossRef Medline

Knapek S, Sigrist S, Tanimoto H (2011) Bruchpilot, a synaptic active zone protein for anesthesia-resistant memory. J Neurosci 31:3453-3458. CrossRef Medline 
Krashes MJ, Keene AC, Leung B, Armstrong JD, Waddell S (2007) Sequential use of mushroom body neuron subsets during Drosophila odor memory processing. Neuron 53:103-115. CrossRef Medline

Lechner HA, Squire LR, Byrne JH (1999) 100 years of consolidationremembering Muller and Pilzecker. Learn Mem 6:77-87. Medline

Lee YS, Carthew RW (2003) Making a better RNAi vector for Drosophila: use of intron spacers. Methods 30:322-329. CrossRef Medline

Liu X, Davis RL (2009) The GABAergic anterior paired lateral neuron suppresses and is suppressed by olfactory learning. Nat Neurosci 12:53-59. CrossRef Medline

Liu X, Buchanan ME, Han KA, Davis RL (2009) The GABAA receptor RDL suppresses the conditioned stimulus pathway for olfactory learning. J Neurosci 29:1573-1579. CrossRef Medline

Livingstone MS, Sziber PP, Quinn WG (1984) Loss of calcium/calmodulin responsiveness in adenylate cyclase of rutabaga, a Drosophila learning mutant. Cell 37:205-215. CrossRef Medline

Maas JW Jr, Vogt SK, Chan GC, Pineda VV, Storm DR, Muglia LJ (2005) Calcium-stimulated adenylyl cyclases are critical modulators of neuronal ethanol sensitivity. J Neurosci 25:4118-4126. CrossRef Medline

McBride SM, Giuliani G, Choi C, Krause P, Correale D, Watson K, Baker G, Siwicki KK (1999) Mushroom body ablation impairs short-term memory and long-term memory of courtship conditioning in Drosophila melanogaster. Neuron 24:967-977. CrossRef Medline

McGuire SE, Le PT, Osborn AJ, Matsumoto K, Davis RL (2003) Spatiotemporal rescue of memory dysfunction in Drosophila. Science 302: 1765-1768. CrossRef Medline

McGuire SE, Mao Z, Davis RL (2004) Spatiotemporal gene expression targeting with the TARGET and gene-switch systems in Drosophila. Sci STKE 2004:pl6. Medline

Michels B, Chen YC, Saumweber T, Mishra D, Tanimoto H, Schmid B, Engmann O, Gerber B (2011) Cellular site and molecular mode of synapsin action in associative learning. Learn Mem 18:332-344. CrossRef Medline

Müller U (2000) Prolonged activation of cAMP-dependent protein kinase during conditioning induces long-term memory in honeybees. Neuron 27:159-168. CrossRef Medline

Nighorn A, Healy MJ, Davis RL (1991) The cyclic AMP phosphodiesterase encoded by the Drosophila dunce gene is concentrated in the mushroom body neuropil. Neuron 6:455-467. CrossRef Medline

Pan Y, Zhou Y, Guo C, Gong H, Gong Z, Liu L (2009) Differential roles of the fan-shaped body and the ellipsoid body in Drosophila visual pattern memory. Learn Mem 16:289-295. CrossRef Medline

Papadopoulou M, Cassenaer S, Nowotny T, Laurent G (2011) Normalization for sparse encoding of odors by a wide-field interneuron. Science 332:721-725. CrossRef Medline

Plaçais PY, Trannoy S, Isabel G, Aso Y, Siwanowicz I, Belliart-Guérin G, Vernier P, Birman S, Tanimoto H, Preat T (2012) Slow oscillations in two pairs of dopaminergic neurons gate long-term memory formation in Drosophila. Nat Neurosci 15:592-599. CrossRef Medline

Qiu Y, Davis RL (1993) Genetic dissection of the learning/memory gene dunce of Drosophila melanogaster. Genes Dev 7:1447-1458. CrossRef Medline

Qiu YH, Chen CN, Malone T, Richter L, Beckendorf SK, Davis RL (1991) Characterization of the memory gene dunce of Drosophila melanogaster. J Mol Biol 222:553-565. CrossRef Medline

Sachse S, Rueckert E, Keller A, Okada R, Tanaka NK, Ito K, Vosshall LB (2007) Activity-dependent plasticity in an olfactory circuit. Neuron 56: 838-850. CrossRef Medline

Schwaerzel M, Monastirioti M, Scholz H, Friggi-Grelin F, Birman S, Heisenberg M (2003) Dopamine and octopamine differentiate between aversive and appetitive olfactory memories in Drosophila. J Neurosci 23: 10495-10502. Medline

Schwaerzel M, Jaeckel A, Mueller U (2007) Signaling at A-kinase anchoring proteins organizes anesthesia-sensitive memory in Drosophila. J Neurosci 27:1229-1233. CrossRef Medline
Séjourné J, Plaçais PY, Aso Y, Siwanowicz I, Trannoy S, Thoma V, Tedjakumala SR, Rubin GM, Tchénio P, Ito K, Isabel G, Tanimoto H, Preat T (2011) Mushroom body efferent neurons responsible for aversive olfactory memory retrieval in Drosophila. Nat Neurosci 14:903-910. CrossRef Medline

Tanimoto H, Heisenberg M, Gerber B (2004) Experimental psychology: event timing turns punishment to reward. Nature 430:983. CrossRef Medline

Technau GM (1984) Fiber number in the mushroom bodies of adult Drosophila melanogaster depends on age, sex and experience. J Neurogenet 1:113-126. CrossRef Medline

Tempel BL, Bonini N, Dawson DR, Quinn WG (1983) Reward learning in normal and mutant Drosophila. Proc Natl Acad Sci U S A 80:1482-1486. CrossRef Medline

Thum AS, Knapek S, Rister J, Dierichs-Schmitt E, Heisenberg M, Tanimoto H (2006) Differential potencies of effector genes in adult Drosophila. J Comp Neurol 498:194-203. CrossRef Medline

Tomchik SM, Davis RL (2009) Dynamics of learning-related cAMP signaling and stimulus integration in the Drosophila olfactory pathway. Neuron 64:510-521. CrossRef Medline

Tully T, Quinn WG (1985) Classical conditioning and retention in normal and mutant Drosophila melanogaster. J Comp Physiol A 157:263-277. CrossRef Medline

Tully T, Preat T, Boynton SC, Del Vecchio M (1994) Genetic dissection of consolidated memory in Drosophila. Cell 79:35-47. CrossRef Medline

Tully T, Bourtchouladze R, Scott R, Tallman J (2003) Targeting the CREB pathway for memory enhancers. Nat Rev Drug Discov 2:267-277. CrossRef Medline

Turner GC, Bazhenov M, Laurent G (2008) Olfactory representations by Drosophila mushroom body neurons. J Neurophysiol 99:734-746. CrossRef Medline

Vosshall LB, Stocker RF (2007) Molecular architecture of smell and taste in Drosophila. Annu Rev Neurosci 30:505-533. CrossRef Medline

Waddell S, Armstrong JD, Kitamoto T, Kaiser K, Quinn WG (2000) The amnesiac gene product is expressed in two neurons in the Drosophila brain that are critical for memory. Cell 103:805-813. CrossRef Medline

Wilson RI, Laurent G (2005) Role of GABAergic inhibition in shaping odorevoked spatiotemporal patterns in the Drosophila antennal lobe. J Neurosci 25:9069-9079. CrossRef Medline

Wilson RI, Turner GC, Laurent G (2004) Transformation of olfactory representations in the Drosophila antennal lobe. Science 303:366-370. CrossRef Medline

Wu CL, Shih MF, Lai JS, Yang HT, Turner GC, Chen L, Chiang AS (2011) Heterotypic gap junctions between two neurons in the Drosophila brain are critical for memory. Curr Biol 21:848-854. CrossRef Medline

Yamazaki D, Horiuchi J, Miyashita T, Saitoe M (2010) Acute inhibition of PKA activity at old ages ameliorates age-related memory impairment in Drosophila. J Neurosci 30:15573-15577. CrossRef Medline

Yin JC, Wallach JS, Del Vecchio M, Wilder EL, Zhou H, Quinn WG, Tully T (1994) Induction of a dominant negative CREB transgene specifically blocks long-term memory in Drosophila. Cell 79:49-58. CrossRef Medline

Yu D, Ponomarev A, Davis RL (2004) Altered representation of the spatial code for odors after olfactory classical conditioning; memory trace formation by synaptic recruitment. Neuron 42:437-449. CrossRef Medline

Yu D, Keene AC, Srivatsan A, Waddell S, Davis RL (2005) Drosophila DPM neurons form a delayed and branch-specific memory trace after olfactory classical conditioning. Cell 123:945-957. CrossRef Medline

Zars T, Fischer M, Schulz R, Heisenberg M (2000) Localization of a shortterm memory in Drosophila. Science 288:672-675. CrossRef Medline

Zhong Y, Wu CF (1991) Altered synaptic plasticity in Drosophila memory mutants with a defective cyclic AMP cascade. Science 251:198-201. CrossRef Medline 